\title{
THE HEAVENLY CALCULUS AND SOCIALLY RESPONSIBLE BUSINESS CONDUCT: AN EXPLORATIVE STUDY AMONG EXECUTIVES*
}

\author{
BY \\ JOHAN GRAAFLAND** AND CORRIE MAZEREEUW-VAN DER DUIJN SCHOUTEN***
}

\begin{abstract}
Summary
In this paper we present a theoretical economic model, describing the influence of eschatological beliefs of executives on their socially responsible business conduct. The core hypothesis is that the belief that one's eternal destination depends on how one behaves in business will provide an incentive to socially responsible business conduct. We confront the model with explorative empirical data, collected by in-depth interviews with and questionnaires among twenty Dutch executives. The data provide weak indications that eschatological beliefs influence the executives' socially responsible business conduct.
\end{abstract}

Key words: business ethics, corporate social responsibility, economics and religion, executives, socially responsible business conduct

JEL Code(s): M14, Z12

\section{INTRODUCTION}

The issue of religiosity in ethical decision-making has received much attention in recent years (Treviño et al. (2000), Giacalone and Jurkiewics (2003), Pava (2003)). Especially, the Protestant work ethic has been a topic of interest (Furnham 1982, 1987). Empirical research shows that this work ethic is associated with certain attitudes about honesty and fairness. For example, Eisenberger and Shank (1985) find that people with a high Protestant work ethic are resistant to cheating.

However, other empirical research indicates that religiousness does not automatically lead to ethical behavior. Guiso, Sapienza en Zingales (2003; cited in Fase (2005)) find that religious people are less inclined to break the

* The authors would like to thank the Dutch Ministry of Economic Affairs and the employers' association VNO-NCW for their financial support. Thanks also to Boaz van Luijk and Aziza Yahia for their assistance in the collection of data used in this paper. We also thank the editor, professor M.M.G. Fase, and two anonymous referees for their valuable suggestions.

** Tilburg University, P.O. Box 90153, 5000 LE, Tilburg, The Netherlands e-mail: j.j.graafland@uvt.nl

*** Tilburg University, P.O. Box 90153, 5000 LE, Tilburg, The Netherlands e-mail: c.vdrduijnschouten@uvt.nl 
law, but also are more intolerant and less progressive towards women. In a number of studies no significant difference has been found between religious and nonreligious individuals with respect to matters such as honest or deceptive behavior. A number of studies even show a negative correlation between religiousness and business ethical judgments, whereas other scenario studies show a positive relationship (Weaver and Agle (2002)). Agle and Van Buren (1999), for example, found a slightly positive correlation between a small set of religious beliefs and attitudes towards, or practices pertaining to corporate social performance. One explanation for these diverse findings is that researches often focus on standard parameters of religiousness, such as affiliation with a specific religious institution, church attendance, or time spent in private devotions that can be applied across several religions. As Weaver and Agle (2002) note, conceptualizing and measuring religiousness in terms of easily observed behavior such as church attendance, risks missing potential motivational and cognitive differences.

In this paper, we focus on one dimension of religiousness, namely eschatological beliefs, and investigate its relationship with socially responsible business conduct (abbreviated in this paper as SRBC) ${ }^{1}$ of executives. The orientation towards the hereafter is a defining characteristic for any religion (Shivesh Chandra Thakur (1969)). An otherworldly orientation directs individual believers to focus on life in the next world and diminishes the importance of temporal concerns. According to Tropman (1995), the different attitudes of executives towards money, work and ethics is related to what he calls 'the heavenly calculus'. The heavenly calculus deals with propositions and explanations about what happens after dying, and how one can control, if at all, death's terms, one's destination after dying, and one's accountability at the time of dying. According to Azzi and Ehrenberg (1975), belief in an afterlife has a major effect on church attendance. But does it also influence behavior in daily life of businessmen? The central research question of this paper is: can we detect an effect of the belief in a hereafter on attitudes and behavior of executives within business organizations? More specific: can we find a relationship between eschatological beliefs and executives' SRBC?

This paper is structured as follows. In the next section, we introduce a multiperiod utility-maximizing model of the relationship between the eschatological beliefs of executives and their business conduct. The purpose of this model is to derive hypotheses about the determinants of SRBC of executives and, in particular, the influence of eschatological beliefs on SRBC. The

1 We use the term SRBC, because it is an overarching concept for the study of businesssociety relationships that can be applied both to the individual and the organizational level (Frooman (1997)). We will focus on the individual level, however. Given the high position in the business hierarchy of the participants in this research project, their individual business conduct can become part of, and contribute to corporate social performance or corporate social responsibility. 
model extends the model of Azzi and Ehrenberg (1975) in various directions, by adding a consumption motive and a social pressure motive, besides a salvation motive. The consumption motive holds that an executive attaches an intrinsic value to SRBC, independently from the consequences it may have during this life or for eternity. The social pressure motive means that the executive is motivated by financial success in this earthly life, and that SRBC may have a positive influence on this success. Other extensions of the model of Azzi and Ehrenberg (1975) are a more detailed analysis of the salvation motive, by distinguishing between the probability of entering heaven and the utility in heaven, and the introduction of time discounting. Section 3 describes the data used in the paper to explore the empirical validity of the hypotheses derived by the theoretical model. In order to collect empirical data, we held in-depth interviews with and set out a questionnaire among twenty Dutch executives. The advantage of interviews is that this method offers the flexibility to ask additional questions in response to the answers of the respondents, including questions about opinions and motives. Thus, this method provides much insight into the perceptions of executives and allows for fine-grained analyses of their religious beliefs. A disadvantage of this method is, however, that interviews are labor intensive. As a result, the sample is relatively small. Therefore, the empirical test of the theoretical model is merely explorative. Section 4 examines the relationship between eschatological beliefs and the executives' SRBC. In section 5 we summarize the main findings of this study and present directions for further research.

\section{THEORETICAL FRAMEWORK}

Eschatological beliefs are expectations about the final destination of mankind. They constitute part of religious beliefs. ${ }^{2}$ In order to derive hypotheses about the relationship between eschatological beliefs and business conduct, we develop a multiperiod utility-maximizing model, akin to Azzi and Ehrenberg (1975). Whereas they use their model to explain church attendance of households, we use a similar framework to explain the relationship between eschatological beliefs and SRBC of executives. The basic hypothesis is that if an executive believes heaven can be 'earned' by acting in accordance with the values and norms implied by one's religious beliefs, this person will act as good as possible to earn this eternal promise. Following Azzi and Ehrenberg, we take the executives' religious beliefs as predetermined. That is, we attempt to explain the SRBC of the executives, given religious belief, rather than religious belief itself.

Our model differs, however, in several aspects. First, whereas Azzi and Ehrenberg assume expected afterlife consumption to be a continuous

2 Religious beliefs is only one of the aspects of religion, which can be defined as 'any shared set of beliefs, activities, and institutions premised upon faith in supernatural forces' (Iannacone (1998)). 
differentiable concave function of the time spent in church-related activities, we make a distinction between two alternative afterlife states; heaven and hell. We assume that SRBC does not only affect the afterlife consumption in each of these states, but also the probability of entering heaven rather than hell. This distinction provides us with a more accurate description how eschatological beliefs may affect business conduct. For example, it allows us to distinguish executives who believe that the eternal destination (heaven or hell) is predetermined or provided by absolution, but also believe that the afterlife consumption within each of these states is affected by their behavior. These executives are different from executives who believe that their business conduct also affects the probability of entering heaven or hell. Second, in contrast to Azzi and Ehrenberg, we make the assumption that people may be shortsighted and discount future benefits, including the utility in the afterlife. This assumption explains why earthly benefits are tradable for afterlife benefits. If afterlife utility would not be discounted, then lifetime is negligible relative to eternity, and the heavenly calculus would entail infinite heavenly utility. Azzi and Ehrenberg avoid this problem by simply assuming that the expected value of afterlife consumption is just one other type of good that is imperfectly substitutable with earthly consumption goods in various periods. Another reason for including time discounting is that this provides an additional reason why religious activity increases with age (one of the observed 'regularities' in the empirical literature, see Ehrenberg (1977) and Iannaccone $\left.(1992)^{3}\right)$. In the model of Azzi and Ehrenberg, the positive relationship between church attendance and age is only guaranteed if the marginal utility of an additional hour of religious activity for two adjacent time periods does not exceed the rate of wage increase minus the market interest rate. Third, whereas Azzi and Ehrenberg posit afterlife consumption as the sole goal of church-related activity, we assume that SRBC does not only affect afterlife utility, but also influences utility in earthly life. ${ }^{4}$ Azzi and Ehrenberg refer to this direct utility effect as the 'consumption motive' (versus the 'salvation motive' that relates church-related activities to afterlife utility). This additional motive provides us with the possibility that religions may motivate executives to SRBC in other ways than by raising afterlife benefits. Fourth, in contrast to Azzi and Ehrenberg, we also take into account of what they call the 'social pressure' motive. This motive refers to the possibility that SRBC (or church participation) will increase the probability of an individual's success in business. This motive seems relevant for the purpose of our

3 Estimates of Long and Settle (1977) do, however, not reveal any significant relationship between church attendance and age.

4 Using a so-called club-model, Iannaccone (1992) even assumes that church-related activities only yields earthly benefits. Our model combines both earthly and eternal benefits from religious motivated actions. 
paper, since the business literature often refers to strategic reasons for SRBC (Graafland and van de Ven (2006)).

Since we extend the model of Azzi and Ehrenberg in four dimensions, we reduce the complexity of the model by simplifying their model in two other dimensions that are less relevant for the purpose of this paper. First, they distinguish between husband and wife in order to explain the allocation of church-related activities in the household. In our model, we disregard from this distinction and assume that the relationship between SRBC and afterlife utility is independent of the actions of the partner of the executive. Second, whereas church attendance is time consuming and, therefore, requires a time allocation model, SRBC is often less time consuming and rather costly in financial terms. We thus assume that SRBC only entails monetary costs and not costs in terms of time forgone.

\subsection{Setup}

We assume that an executive believes in the existence of eternal heaven and hell and that he has probability $f$ to enter heaven. The utility function is:

$$
u=\sum_{t=0}^{t=k} n\left(c_{t}, s_{t}\right) /(1+\rho)^{t}+\sum_{t=k+1}^{t=\infty}\left(f\left(s_{t}\right) \bar{u}\left(s_{t}\right)+\left(1-f\left(s_{t}\right)\right) \underline{u}\left(s_{t}\right)\right) /(1+\rho)^{t}(1)
$$

In this utility function, $u$ denotes total utility, $k$ the expected number of years still living on earth, $n$ the annual utility during this earthly life, $c$ consumption, $s$ the level of SRBC, $\rho$ the rate of time preference, $f$ the probability to enter heaven upon dying (and $1-f$ the probability to enter hell), $\bar{u}$ the perceived (annual) utility during the state of heaven and $\underline{u}$ the perceived (annual) utility during the state of hell, with $\bar{u} \geq \underline{u}$. Following Azzi and Ehrenberg, we assume for simplicity that the executives know the length of their life. The utility function of executives believing that all people will immediately enter heaven upon dying, or executives who do not believe in a hereafter can be specified as specific cases of equation (1). In the first case, $f=1$, and in the latter case, $\underline{u}$ and $\bar{u}$ are zero.

We assume that SRBC potentially has a constant and positive effect on heavenly utility, hellish utility and the probability of entering heaven or hell (i.e. $\partial \bar{u} / \partial s_{t} \geq 0 ; \partial \underline{u} / \partial s_{t} \geq 0 ; \partial f / \partial s_{t} \geq 0$ ), but that the second-order influence of $s$ is negative (i.e. $\partial^{2} \bar{u} / \partial s_{t}^{2} \leq 0, \partial^{2} \underline{u} / \partial s_{t}^{2} \leq 0$ and $\partial^{2} f / \partial s_{t}^{2}<0$ ). Furthermore, we simplify the model by assuming that the effects of SRBC on heavenly and hellish utility are equal (i.e. $\partial \bar{u} / \partial s_{t}=\partial \underline{u} / \partial s_{t}$ ).

The annual utility function $(n)$ is specified as in Graafland (2002a). The utility experienced during earthly life depends on consumption (c) and on SRBC (as an intrinsic goal). We apply standard assumptions of concavity $\left(\partial n / \partial c_{t}>0, \partial^{2} n / \partial c_{t}^{2}<0, \partial n / \partial s_{t}>0, \partial^{2} n / \partial s_{t}^{2}<0, \partial\left(\partial n / \partial c_{t}\right) / \partial s_{t}=\right.$ 
$\left.\partial\left(\partial n / \partial s_{t}\right) / \partial c_{t}>0\right)$. The direct effect of SRBC on annual earthly utility reflects the 'consumption motive' and expresses current satisfaction from SRBC.

Furthermore, we assume that SRBC may also potentially affect the executive's succeeding in business (the social-pressure motive) by factor $v$, and that the executive plans to leave no estate. Let $z_{t}$ denote real income in any time period, and let $i$ denote a constant market rate of real interest. Given that, the lifetime discounted income constraint is given by:

$$
\sum_{t=0}^{t=k}\left(c_{t} /(1+i)\right)^{t}=\sum_{t=0}^{t=k}\left(\left(z_{t}+v\left(s_{t}\right)\right) /(1+i)\right)^{t}
$$

The net effect of SRBC on real income $\left(\partial v / \partial s_{t}\right)$ may either be positive or negative. On the one hand, SRBC may be costly and reduce income. On the other hand, SRBC may generate positive reputation effects that will contribute to the financial success of the executive (Graafland (2002a,b); Graafland and Smid (2004)). Religious executives may also believe that such positive effects are caused by divine interaction: God rewards good behavior and punishes bad behavior already during this earthly life (Tamari (1997)). Religious texts, such as those of the Old Testament's Wisdom writers, stress that wealth is a reward for an active and virtuous life (Graafland (2001)).

\subsection{First Order Conditions}

We can write the Lagrangian function for the problem as:

$$
\begin{aligned}
\operatorname{Max} L\left(c_{t}, s_{t}\right)= & \sum_{t=0}^{t=k} n\left(c_{t}, s_{t}\right) /(1+\rho)^{t}+\sum_{t=k+1}^{t=\infty}\left(f\left(s_{t}\right) \bar{u}\left(s_{t}\right)\right. \\
& \left.+\left(1-f\left(s_{t}\right)\right) \underline{u}\left(s_{t}\right)\right) /(1+\rho)^{t} \\
& +\lambda \sum_{t=0}^{t=k}\left\{\left(c_{t}-z_{t}-v\left(s_{t}\right)\right) /(1+i)^{t}\right\}
\end{aligned}
$$

Let $b=1 /\left(\rho(1+\rho)^{k}\right)$. Using $\partial \bar{u} / \partial s_{t}=\partial \underline{u} / \partial s_{t}$ (see above) and assuming that an interior solution occurs (see below), the first order condition for an optimum level of SRBC is:

$$
\begin{aligned}
\partial L / \partial s_{t}= & -\lambda \quad \partial v / \partial s_{t} /(1+i)^{t}+\partial n / \partial s_{t} /(1+\rho)^{t}+b\left(\partial f / \partial s_{t}\left(\bar{u}\left(s_{t}\right)\right.\right. \\
& \left.\left.-\underline{u}\left(s_{t}\right)\right)+\partial \bar{u} / \partial s_{t}\right)=0
\end{aligned}
$$

The first order condition for an optimum level of consumption is:

$$
\partial L / \partial c_{t}=\partial n / \partial c_{t} /(1+\rho)^{t}+\lambda /(1+i)^{t}=0
$$


or:

$$
\lambda=-\partial n / \partial c_{t}(1+i)^{t} /(1+\rho)^{t}
$$

Substitution of equation (6) into (4) yields:

$$
\begin{aligned}
\partial L / \partial s_{t}= & \left(\partial n / \partial c_{t} \partial v / \partial s_{t}\right) /(1+\rho)^{t}+\partial n / \partial s_{t} /(1+\rho)^{t}+b\left\{\partial f / \partial s_{t}\left(\bar{u}\left(s_{t}\right)\right.\right. \\
& \left.\left.-\underline{u}\left(s_{t}\right)\right)+\partial \bar{u} / \partial s_{t}\right\}=0
\end{aligned}
$$

The first term in equation (7) expresses the extrinsic motivation to SRBC, because of its influence on earthly consumption (social pressure motive). The second term expresses the intrinsic motivation to SRBC, independent from earthly monetary or eternal benefits (the consumption motive). The third term expresses the eternal pay-off from SRBC, because it increases the probability of a heavenly destination and affects the utility in heaven (the salvation motive).

Furthermore, note that, since the consumption motive and salvation motive yield a non-negative influence of SRBC on utility, equation (7) implies that, at the point where total utility is maximized, the social pressure motive must yield a non-positive effect of SRBC on monetary income:

$$
\begin{aligned}
\partial v / \partial s_{t}= & \left\{-\partial n / \partial s_{t}-b(1+\rho)^{t} \partial f / \partial s_{t}\left(\bar{u}\left(s_{t}\right)-\underline{u}\left(s_{t}\right)\right)\right. \\
& \left.-b(1+\rho)^{t} \partial \bar{u} / \partial s_{t}\right\} / \partial n / \partial c_{t}
\end{aligned}
$$

However, this does not exclude the possibility that $\partial v / \partial s_{t}$ is also positive. Indeed, many empirical researches find a positive relationship between SRBC and profitability (Posnikoff, 1997; Waddock and Graves, 1997; Orlitzky Schmidt and Rynes, 2003). ${ }^{5}$ But it implies that the win-win perspective is limited to a certain degree. Thus, although $\partial v / \partial s_{t}$ may be initially positive, the monetary returns from SRBC are likely to fall, whereas the costs generated by more SRBC will probably increase, and at a certain point, the marginal impact of SRBC on consumption will become negative. Hence, equation (8) implies either that $\partial v / \partial s_{t}$ is unambiguously negative, or that the second order effect of SRBC on consumption is negative, i.e. $\partial^{2} v / \partial s_{t}^{2}<0$. If $\partial v / \partial s_{t}$ would be unambiguously positive, the maximization problem cannot be solved and implies infinite consumption and SRBC.

\subsection{Hypotheses Implied by the Model}

In order to derive hypotheses of the qualitative effects of various variables distinguished in our model, we take the total differentiation of (7). This gives

5 There are, however, several other studies that find a neutral or negative relationship between profits and principles. See Jones and Wicks (1999) and McWilliams and Siegel (2001). 
(for $\mathrm{t}=0)$ :

$$
\begin{aligned}
g_{1} \Delta s= & g_{2} \Delta z+g_{3} \Delta(\partial n / \partial c)+g_{4}(\Delta \partial v / \partial s)+a \Delta(\partial n / \partial s) \\
& +g_{5} \Delta k+b(\bar{u}-\underline{u})(\Delta \partial f / \partial s)+b \partial f / \partial s(\Delta \bar{u}-\Delta \underline{u}) \\
& +b \Delta(\partial \bar{u} / \partial s)+g_{6} \Delta \rho
\end{aligned}
$$

where $\Delta s$ denotes an increase in $s$ and:

$$
\begin{aligned}
g_{1}= & -\left\{\partial n / \partial c \partial^{2} v / \partial s^{2}+\partial v / \partial s(\partial(\partial n / \partial c) / \partial s)+\partial^{2} n / \partial s^{2}+b \partial^{2} \bar{u} / \partial s^{2}\right. \\
& \left.\quad+b(\bar{u}-\underline{u}) \partial^{2} f / \partial s^{2}\right\}>0 \\
g_{2}= & \left\{\partial v / \partial s \partial^{2} n / \partial c^{2}+(\partial(\partial n / \partial s) / \partial c)\right\} \partial c / \partial z>0 \\
g_{3}= & \partial v / \partial s \leq 0 \\
g_{4}= & \partial n / \partial c>0 \\
g_{5}= & \partial \bar{u} / \partial s \partial b / \partial k+(\bar{u}-\underline{u}) \partial f / \partial s \partial b / \partial k \leq 0 \\
g_{6}= & -(\partial \bar{u} / \partial s+\partial f / \partial s(\bar{u}-\underline{u}))(b(1 / \rho+k /(1+\rho))) \leq 0
\end{aligned}
$$

The equation for $g_{1}$ reflects the second order condition for maximal utility. Since all terms within brackets are negative, this condition is met.

From equation (9) we derive three hypotheses that are also implied by the model of Azzi and Ehrenberg, namely that SRBC will be higher if:

1 The executive has a higher real income ( $z$ is higher)

2 The executive is less concerned about earning a high personal income (i.e. if $\partial n / \partial c$ is lower).

3 The life expectation of the executive $(k)$ is shorter.

The third hypothesis, relating age to SRBC, is based on another mechanism than in the model of Azzi and Ehrenberg. In their model the positive relationship between church attendance and age results if the marginal utility of an additional hour of religious activity for two adjacent time periods does not exceed the rate of wage increase minus the market interest rate. In equation (9) this age effect works through the real income effect $(z)$. But our model provides an additional reason why SRBC might be positively related to age: as a result of time discounting, the relative weight of the eternal future in total utility increases if one's life expectation decreases. Assuming that the expected age of dying is the same for all executives, this means that older executives will be more inclined to perform SRBC, because they attach a relatively higher value to their eternal destination. ${ }^{6}$

6 Another explanation for a positive age effect on church attendance is religious human capital, defined as the stock of religion-specific experience derived from one's past religious activities (Iannaccone (1998)). This can be specified as a model of religious habit in which participation can grow over time due to 'addiction'. Furthermore, age may represent cultural effects. As the elderly belong to an older generation that is used to attend church, they may face higher social pressure from their social environment to behave in accordance to the social norms of religious groups. 
On top of these three hypotheses, we derive three other hypotheses connecting SRBC to eschatological beliefs that are more specific than in the model of Azzi and Ehrenberg, namely that SRBC will be higher if:

4 The perceived influence of SRBC on the probability to enter heaven $(\partial f / \partial s)$ is higher, at least if heavenly utility exceeds hellish utility $(\bar{u}>\underline{u})$.

5 The perceived difference between the heavenly utility and the hellish utility is higher (i.e. $\bar{u}-\underline{u}$ is higher), at least if SRBC affects one's eternal destination $(\partial f / \partial s>0)$.

6 The perceived influence of SRBC on heavenly utility is higher (i.e. $\partial \bar{u} / \partial \mathrm{s}$ is higher).

Finally, our model adds three new hypotheses to the Azzi and Ehrenberg's model (1975) because of the addition of a consumption motive, social pressure motive and time discounting. These hypotheses state that SRBC will be higher if:

7 The executive attaches a higher intrinsic value to SRBC (i.e. if $\partial n / \partial s$ is higher).

$8 \mathrm{SRBC}$ has a more positive influence on real income (i.e. if $\partial v / \partial s$ is higher).

9 The executive has a lower rate of time preference $(\rho)$ : executives with a high rate of time preference will take less account of the consequences of SRBC on eternal utility compared to executives with a low rate of time preference.

In the extreme case of no discounting $(\rho=0), b$ is infinite. ${ }^{7}$ In that case, equation (7) can be simplified to:

$$
\partial f / \partial s(\bar{u}-\underline{u})+\partial \bar{u} / \partial s=0
$$

and equation (9) boils down to:

$$
\Delta s=\{(\bar{u}-\underline{u}) \Delta(\partial f / \partial s)+\partial f / \partial s(\Delta \bar{u}-\Delta \underline{u})+\Delta(\partial \bar{u} / \partial s)\} / g_{1^{\prime}}
$$

with $g_{1^{\prime}}=-\left\{\partial^{2} \bar{u} / \partial s^{2}+(\bar{u}-\underline{u}) \partial^{2} f / \partial s^{2}\right\}>0$. In this case, SRBC is only driven by the salvation motive. The consumption motive and the social pressure motive are of no importance anymore. Following from this, only hypotheses (4) to (6) remain relevant.

7 Some religions reject time discounting. Also some medieval scholars rejected time discounting and the practice of demanding interest for loans. The idea was that the lender sells nothing but time, which belongs to God. Hence, the lender steals from God if he demands interest. Time is commune omnium (Le Goff (1986)). 


\section{SAMPLE}

In order to collect empirical data, we held in-depth interviews with and set out a questionnaire among twenty executives with a Dutch nationality. This methodology differs in several aspects from most other research on the relationship between religiousness and business conduct. First, whereas most research focus on persons from the USA and undergraduate or MBA student samples (Angelidis and Ibrahim (2004)), our sample concerns Dutch executives. Second, we both used interviews, as well as questionnaires. Whereas the interviews focused on the religiousness or spirituality of the executives, the questionnaires asked for their views of, and contributions to SRBC.

Our sample consists of twenty corporate executives. Table 1 reports the main background characteristics of the respondents. To ensure the study's inclusiveness, we selected a cross-section of executives with different religious backgrounds. The sample consisted of three Roman Catholics, eight Protestants, ${ }^{8}$ five practitioners of Zen meditation, two Muslims, one Jew, and one Atheist. The practitioners of Zen meditation often uphold a mixed belief system, combining elements of Christianity (Protestant or Catholic) and Buddhism. The names and addresses were obtained from the Dutch employers' organization VNO-NCW. Most interviewees are male $(95 \%)$ and have advanced education. ${ }^{9}$ The interviewees cover a diverse range of industries. All interviewees hold high senior positions in their organization. We focused on senior executives, because of their level of autonomy and discretionary authority to develop a social strategy for their firm (Hambrick and Mason (1984), Lerner and Fryxell (1994), Buchholtz et al. (1999), Werbel and Carter (2002)). This means they are likely to be less dependent on the views of others within their organization than the average manager. The number of employees within the company of the interviewed executives is very diverse.

\subsection{Interviews}

First, we held in-depth interviews with the 20 executives. The advantage of in-depth interviews is that they allow a very detailed analysis of the topic of research (Liedtka (1991)). This is especially important for our research subject, since religious beliefs are often highly complex and cannot readily be categorized. Instead of using predetermined categorizations, in-depth interviews allow to ask open questions, offering the interviewees the opportunity

8 The group of Protestant executives consisted of two Calvinist, two Evangelical and four other Protestant executives.

9 University means university doctoral degree. High means high vocational training. Secondary means secondary vocational training. 
TABLE 1 - BACKGROUND CHARACTERISTICS OF THE INTERVIEWEES

\begin{tabular}{llllll}
\hline $\begin{array}{l}\text { Characterization } \\
\text { religious belief }\end{array}$ & $\begin{array}{l}\text { Size of } \\
\text { organization }^{\text {a }}\end{array}$ & Current position & $\begin{array}{l}\text { Education } \\
\text { level }\end{array}$ & Age & Type of industry \\
\hline Catholic & 1,200 & CEO & University & 58 & Insurance \\
Catholic & 200 & Director & High & 53 & Construction \\
Catholic & 500 & Director-owner & High & 54 & Consumer products \\
Protestant & 130 & General director & High & 51 & Construction \\
Protestant & 40 & Partner-owner & Secondary & 67 & Agriculture \\
Protestant & 165 & Commercial director & High & 42 & Consultancy \\
Protestant & 320 & General director & University & 45 & Consumer products \\
Protestant & 500 & Director-owner & High & 69 & Electronics \\
Protestant & 55 & Partner-owner & University & 42 & Accounting \\
Protestant & 170 & Director & High & 40 & Consultancy \\
Protestant & 120 & Director & University & 52 & Communications \\
Zen & Variable & Director-owner & High & 43 & Consultancy \\
Zen & 35 & Partner-owner & University & 47 & Finance \\
Zen & 10,000 & CEO & University & 57 & Finance \\
Zen & 1,100 & CEO & High & 40 & Health care \\
Zen & Variable & Interim manager & Secondary & 48 & Health care \\
Muslim & 16 & Senior manager & University & 53 & Electronics \\
Muslim & 30 & General director & Secondary & 42 & Food \\
Jewish & 3 & Director & University & 55 & Real estate \\
Atheist & 35 & Director & High & 51 & Consultancy \\
\hline
\end{tabular}

${ }^{a}$ Measured by the number of employees working within the company. ${ }^{10}$

to answer freely without any framework presented by the researcher. For the researcher it raises the opportunity to use a categorization that fits the given answers when analyzing the interviews afterwards or, if applicable, even to develop a new categorization that can also be used in further research. Moreover, in-depth interviews offer the opportunity to ask for more explanation of the viewpoints of the interviewee and to ask several control questions to check the consistency of the answers given. This offers deeper insight in the belief system of the interviewees. For example, one of the interviewees answered to the question 'do you belief in a hereafter' as follows: "according to the Koran I should believe in a hereafter, but the realistic part of myself denies the possibility of a hereafter". The discussion that followed reveals the viewpoint of the interviewee with respect to the hereafter more clearly. When he, for example, states that someone will go to hell, he means that other persons will maintain a negative remembrance to this person after his death. This indicates that this respondent denies the existence of an eternal hereafter.

10 Two interviewees work as a consultant in different companies and in different teams. Therefore, the size of their organization is variable over time. In the statistical analysis we applied the category "very small organization" $(<10)$ in these cases. 
As shown by this example, in-depth interviews also minimize the social desirability bias. Instead of answering the viewpoint of the Islam, he presents both: the viewpoint of Islam and his own point of view, that, in case, differs widely from the social desirable answer within his religious framework. Another reason for conducting in-depth interviews is that our research is exploratory in nature and still in the theory-building phase. ${ }^{11}$

Of course, in-depth interviews also have some disadvantages (Liedtka (1991)). In particular, because of the labor-intensiveness of this research method, the sample is necessarily much smaller than samples obtained by other research methods, such as questionnaires. The results of the interviews can, therefore, not be held as representative of the total population of executives. Care must be taken in interpreting the results, and given the exploratory nature of this study, the findings should be tested on a larger scale.

The interviews took approximately two hours per person, and were recorded and transcribed. The major part of the interviews dealt with the religious beliefs of the executives. In this paper, we analyse the questions about their eschatological expectations to derive qualitative measures of the variables describing the influences of SRBC on one's eternal destination or heavenly utility as distinguished in section 2. For this purpose, the research included, among others, the following questions: do you believe in heaven and hell? If yes: what are the conditions to enter heaven or hell? What are the characteristics of heaven and hell?

Two researchers of our group independently analyzed the content of each interview with reference to a fixed set of questions. The agreement in the coders' classification of aspects of the eschatological beliefs of the interviewees, varied between 70 and 100 percent. From this information we constructed two binary variables concerning the influence of SRBC on the eternal destination respectively on the heavenly utility (with value 0 expressing no influence and value 1 expressing a positive influence) that allows us to test hypothesis 4 and 6. ${ }^{12}$

Five of the interviewed executives believe that doing good works increases the probability that someone enters heaven. As stated by hypothesis 4, this will only influence their SRBC if they also believe that heavenly utility exceeds hellish utility. For all but one of these five executives, this was indeed the case. ${ }^{13}$ The fifteen other executives deny an influence of good works on the

11 Weaver and Agle (2002) also point out that given the minute amount of existing research on religion's impact on ethical behavior in organizations, much research in this area will need to be of a qualitative, concept- and theory-building character.

12 Since hypothesis 5 implies that the difference between heavenly and hellish utility will only affect SRBC if it is combined with the belief that SRBC affects the eternal destination, and since we only construct qualitative information about the eschatological beliefs, we cannot test hypothesis 5 independently from hypothesis 4 .

13 The fifth executive believes that people with an evil state of mind will feel comfortable in hell, whereas people with a good state of mind will feel comfortable in heaven. 
eternal destination. Six of them believe in heaven and hell, but reject an influence of SRBC on the probability of entering heaven, because they believe in grace or predestination as the basis to enter heaven. Five other executives only believe in a heaven and not in a hell. Therefore, they do not believe that contributing to SRBC influences the probability to enter heaven, because everyone will enter heaven anyhow. Finally, four interviewees reject an influence of SRBC on the eternal destination, because they do not believe in a hereafter. $^{14}$

With respect to the second variable, two of the interviewed executives believe that contributing to SRBC increases the heavenly utility. As stated by one of them: "I believe that difference in rewarding will be based on the things we did on earth. Rewarding will be based on good works." The other executives do not believe that contributing to SRBC will have any impact on the heavenly utility.

\subsection{Questionnaire}

By means of the questionnaire we collected information about the SRBC of the respondents. In order to minimize the social desirability response bias, we assured the participants that their identity would remain confidential. The executives thus had no reason to present a non-realistic and more favorable picture of their SRBC. Moreover, the questionnaires were sent four months after the interviews. The time lag of four months between the interviews and the questionnaire reduces the probability of social desirability response biases in answering the questions regarding SRBC, which may arise if religiousness and behavioral aspects are assessed simultaneously (Giacalone and Jurkiewics (2003)). Insofar as social desirability response biases are still present in the responses, we think these will not influence our analysis of the relationship between eschatological expectations and SRBC, because there is no reason why executives who do not believe in heaven and/or hell would have larger or smaller biases than managers who do believe in a hereafter. ${ }^{15}$

The executives (self-reported) own contribution to SRBC was measured by their response to three questions. Do you personally make efforts to stimulate your company's contribution to SRBC? Did you ever take some initiatives to foster SRBC in your company? Do other persons in your company regard you as pro-active with respect to SRBC? Each variable is mea-

14 So, on average, $80 \%$ of the interviewees believe in heaven and $55 \%$ believe in hell. This is similar to the outcomes of polls of religious belief in the USA (Iannaccone (1998)), but is rather high compared to the average belief in heaven and hell in The Netherlands. In The Netherlands, $37 \%$ of the people believes in heaven, whereas only $9 \%$ believe in hell (Kaski (2004)).

15 Another problem is that the data collected reflect the perceptions of the respondents rather than their actual SRBC. However, it is difficult to obtain more objective information about the business conduct of individual executives. 
TABLE 2 - OUTCOMES OF THE QUESTIONNAIRE

\begin{tabular}{lllll}
\hline & $\begin{array}{l}\text { Own } \\
\text { contribution } \\
\text { to SRBC }\end{array}$ & $\begin{array}{l}\text { Importance } \\
\text { of high } \\
\text { profitability }\end{array}$ & $\begin{array}{l}\text { Strategic } \\
\text { value of } \\
\text { SRBC }\end{array}$ & $\begin{array}{l}\text { Intrinsic } \\
\text { value of } \\
\text { SRBC }\end{array}$ \\
\hline $\begin{array}{l}\text { Average value } \\
\text { Standard deviation }\end{array}$ & 3.52 & 3.70 & 3.85 & 4.10 \\
0.80 & 0.66 & 0.93 & 1.02 \\
\hline
\end{tabular}

sured on a 5 -point scale $(1=$ no; $2=$ somewhat $3=$ quite much; $4=$ much; $5=$ very much). In the questionnaire, these three questions were preceded by seventeen other questions that asked the executive's valuation of the importance of specific aspects of SRBC distinguished by Graafland and Eijffinger (2004), such as employee health and safety, offering equal employment and career opportunities to women and ethnic minorities, support of local community projects and projects in third world countries, respect of suppliers and customers, and reduction of environmental damage. These questions serve the purpose of providing the executives with an inductive idea of the meaning of SRBC. They do not inform us, however, about the conduct of the executives (which is the subject of this paper), but merely about their views of the importance of various aspects of SRBC. We grouped the answers to the three 'contribution' questions into one variable and checked whether this clustering of data is empirically justified by computing the so-called Cronbach's alpha. The Cronbach's alpha for the three questions is 0.81 . This is well above the lower limit for acceptability with respect to internal reliability of this measure, which is considered to lie between 0.6 and 0.7 ( Hair et al. (1998)). ${ }^{16}$ Moreover, according to Schmitt (1996) variables may be clustered into one if they have a meaningful content coverage. In this case, the three questions have a very strong content coverage, each of them measuring the executives' contribution to SRBC in other formulations.

The questionnaire also contains information about several explanatory variables (see Table 2). First, the marginal utility of consumption $(\partial n / \partial c)$ is approximated by the respondents' response to the question: How much value do you attach to high profitability? $(1=$ no; $2=$ somewhat $3=$ quite much; $4=$ much; $5=$ very much $)$. Second, the strategic value of SRBC $(\partial v / \partial s)$ was tested by the following statement: 'Our firms' own effort with respect to SRBC will have a positive influence on our trading results in the long term'. Agreement with this statement indicates a positive valuation of the strategic dimension of SRBC. Third, the intrinsic value of SRBC $(\partial n / \partial s)$ is measured by the respondents' answers to the statement: 'To behave in a responsible way

16 Cronbach's alpha is a statistic to test the reliability of a composed variable. Normally, a concept is measured by several questions. Cronbach's alpha gives an indication of the consistency in the responses to the different questions. 
is a moral duty of businesses towards society'. Agreement with this assertion, indicates an explicitly ethical approach to SRBC. The respondents were asked to indicate on a 5-point scale to what extent they agreed with these statements $(1=$ completely disagree; $2=$ disagree; $3=$ neutral; $4=$ agree; $5=$ completely agree). Table 2 shows that, on average, the executives give more support to the ethical approach compared to the strategic approach of SRBC. Finally, unfortunately, we do not have any information about the income of the executives and their rate of time preference.

\section{ESCHATOLOGICAL BELIEFS AND SOCIALLY RESPONSIBLE BUSINESS CONDUCT}

To test the formulated hypotheses, we carried out a partial correlation analysis and a linear multivariate regression analysis ${ }^{17}$. The results of these analyses will be presented in this section.

\subsection{Partial Correlation Analysis}

First, we carried out a partial correlation analysis between the dependent and explanatory variables. As control variables we used the size of the organization (6 point scale: $0-10,11-50,51-100,101-250,251-500$ and over 500 employees) and the educational level of the interviewees ( 3 point scale: secondary, high or university). Table 3 shows the results of the correlation analysis.

The results show several significant correlations. First, executives believing that SRBC influences the heavenly utility seem to contribute more to SRBC compared to executives not believing in an influence of SRBC on heavenly utility. Second, we find a positive correlation between the intrinsic and strategic value of SRBC. This indicates that strategic and intrinsic motivation to SRBC reinforce each other. Finally, we also find a positive correlation between strategic motivation and the age of the executive. Thus, it seems that the older executives perceive a more positive relationship between financial business success and SRBC than young executives.

\subsection{Multivariate Regression Analysis}

To analyze further the relationship between the heavenly calculus and SRBC, we also carried out a multiple regression analysis. We added square age in order to control for non-linearity in the relationship between SRBC and age. Table 4 reports on the outcomes of the regression analysis.

17 We also considered the use of ordered probit or ordered logit analysis. However, ordered probit and ordered logit analyses are only applicable to large samples. Since we have only 20 observations, probit or logit analysis is not suitable. In cases of small samples linear regression is commonly used. 
TABLE 3 - PARTIAL CORRELATION ANALYSIS a,b

\begin{tabular}{lcccccc}
\hline & $\begin{array}{l}\text { Contribution } \\
\text { to SRBC }\end{array}$ & $\begin{array}{l}\text { Influence on } \\
\text { destination }\end{array}$ & $\begin{array}{l}\text { Influence } \\
\text { on utility }\end{array}$ & $\begin{array}{l}\text { Importance } \\
\text { profitability }\end{array}$ & $\begin{array}{l}\text { Intrinsic } \\
\text { value }\end{array}$ & $\begin{array}{l}\text { Strategic } \\
\text { value }\end{array}$ \\
\hline Influence of SRBC on & -0.14 & & & & & \\
eternal destination & $(0.59)$ & & & & & \\
Influence of SRBC on & 0.42 & -0.35 & & & & \\
heavenly utility & $(0.09)$ & $(0.15)$ & & & & \\
Importance of & -0.14 & 0.35 & -0.08 & & & \\
profitability & $(0.58)$ & $(0.15)$ & $(0.76)$ & & & \\
Intrinsic value & -0.12 & -0.02 & -0.10 & 0.28 & & \\
of SRBC & $(0.67)$ & $(0.95)$ & $(0.69)$ & $(0.27)$ & & \\
Strategic value & 0.32 & 0.25 & 0.08 & 0.37 & $\mathbf{0 . 5 3}$ & \\
of SRBC & $(0.19)$ & $(0.32)$ & $(0.77)$ & $(0.13)$ & $\mathbf{( 0 . 0 3 )}$ & \\
Age & 0.22 & 0.29 & 0.04 & -0.07 & 0.36 & $\mathbf{0 . 6 7}$ \\
& $(0.38)$ & $(0.24)$ & $(0.89)$ & $(0.78)$ & $(0.14)$ & $\mathbf{( 0 . 0 0 )}$ \\
\hline
\end{tabular}

${ }^{\text {a }}$ Controlled for size of organisation and educational level

${ }^{\mathrm{b}} p$-values in parentheses; italics: $p<0.10$; bold : $p<0.05$

In the first column, all variables are included. For most variables the sign of the parameter is in accordance with the hypotheses of the theoretical model, but none of them is found to exert a significant influence on SRBC.

In the second column, we dropped the intrinsic value of SRBC, because this variable is correlated with the extrinsic value of SRBC (see Table 3), which may cause multicollinearity in the multivariate regression analysis.

\section{TABLE 4 - ESTIMATION RESULTS OF MULTIVARIATE REGRESSION}

\begin{tabular}{lcc}
\hline Variable & Parameter $(t$-statistic) & Parameter $(t$-statistic) \\
\hline Influence of SRBC on eternal destination & $0.08(0.14)$ & $0.28(0.52)$ \\
Influence of SRBC on heavenly utility & $0.67(1.07)$ & $0.83(1.38)$ \\
Importance of profitability & $-0.22(0.64)$ & $-0.29(0.87)$ \\
Strategic value of SRBC & $0.50(1.70)$ & $0.42(1.50)$ \\
Intrinsic value of SRBC & $-0.19(0.94)$ & \\
Age & $-0.44(1.66)$ & $-0.47(1.81)$ \\
0.01 Age $^{2}$ & $0.40(1.63)$ & $0.43(1.76)$ \\
Size of organization & $-0.16(1.34)$ & $-0.14(1.11)$ \\
Education & $-0.02(0.07)$ & $-0.14(0.48)$ \\
Constant & $15.43(2.30)$ & $16.18(2.45)$ \\
$R^{2}$ & 0.78 & 0.76 \\
$F$-value & 1.71 & 1.82 \\
\hline
\end{tabular}


Although all parameters remain insignificant (which may be due to the small sample), the estimation results show a weak indication that the heavenly calculus has some relevance for the SRBC of executives. In particular, we find that executives believing that good works have a positive impact on heavenly utility seem to be more involved with SRBC than other executives. In contrast, the belief that good works affect the eternal destination hardly influences SRBC. Furthermore, we find that the value that the executive attaches to high profitability has a negative impact on SRBC, which is in line with hypothesis two, but the parameter is highly insignificant. The strategic value of SRBC is found to have a positive influence on SRBC. This result is in line with research by Graafland and van de Ven (2006), who found that corporate social performance is partly driven by strategic motivations, but they find that intrinsic motivations are even more important ${ }^{18}$. Furthermore, we find a negative influence of age, which is opposite to hypothesis three. The negative effect is, however, decreasing with age. Finally, whereas the educational level seems hardly relevant, the other control variable, the size of the organization, tends to have a negative effect on the contribution to SRBC. ${ }^{19}$

What do the estimation results tell us about the theoretical model as developed in section two and, in particular, the extensions we proposed and tested in comparison to the model of Azzi and Ehrenberg? First, the consumption motive seems not to add to the explanatory power of the model, since we found no positive influence of an intrinsic value of SRBC on the executives' SRBC. Second, introducing time discounting also seems redundant, showing a negative, instead of the expected positive, age effect. The estimation results rather indicate the relevance of Azzi and Ehrenberg's theoretical result that religious motivated actions decrease with age if wage profiles are steep. The positive effect of squared age in Table 4 confirms this hypothesis, because the steepness of wage profiles usually decreases with age.

On the other hand, the estimation results seem to provide weak empirical evidence for the relevance of making a distinction between the belief that good works affects the eternal destination and the belief that good works affects heavenly utility. Whereas the first variable seems irrelevant, we find a weak empirical indication that the second variable contributes to a relatively high level of SRBC. Furthermore, the estimation results also provide a weak empirical indication for the relevance of the social pressure motive, since the strategic value of SRBC shows a positive, although insignificant, influence on SRBC.

18 For a sample of 111 Dutch companies, they find a partial correlation coefficient between the contribution to SRBC on the one hand and intrinsic and strategic motivation (similarly defined as in this paper) on the other hand of 0.35 and 0.10 respectively.

19 If it is assumed that the size of organization and educational level are proxies for the income of the executives, these results indicate that hypothesis 1 (that income stimulates SRBC) is not confirmed. 


\section{SUMMARY AND CONCLUSION}

In this paper we investigate the relationship between eschatological beliefs and the business conduct of executives. We developed a theoretical model of the eschatological incentives for executives to socially responsible business conduct (SRBC). In comparison to existing models, we derive some new hypotheses. First, the level of SRBC is related to the executive's perception of the relationship between SRBC and financial success, be it by human causes or by supra-natural causes (i.e. God's blessing during this earthly life as a response to living a holy life). Second, the executive will be more motivated to SRBC, if he attaches an intrinsic value to this type of conduct, independent from the consequences it may have during this life or for eternity. Third, the level of SRBC is negatively related to the rate of time preference, because executives with a high rate of time preference will take less account of the consequences of SRBC on eternal utility compared to executives with a low rate of time preference.

In addition, our model gives a more detailed analysis how eschatological beliefs may influence business behaviour. Whereas other models describe eternal utility by one factor, we distinguish between the probability to enter heaven (rather than hell), utility in the heavenly state, and utility in the hellish state. These refinements allow us to distinguish between executives believing that SRBC affects the afterlife consumption in heaven or hell from executives believing that their business conduct (also) affects the probability of entering heaven or hell.

In order to gain exploratory insight into the relevance of these hypotheses, we held in-depth interviews with twenty Dutch executives with various religious backgrounds. The results of the interviews are used to identify qualitative measures of the eschatological variables in our model. Four months after the interviews we sent out a questionnaire to collect other data necessary to test the model.

The estimation results tend to support some of the hypotheses we derived for the relationship between eschatological beliefs and SRBC. Although we find no influence of the belief that good works influence the eternal destination, the belief that good works influence the heavenly utility shows a significant positive relationship with SRBC in a partial correlation analysis. A multiple regression analysis also gives a positive, but insignificant, relationship between an executives influence on heavenly utility and SRBC. Furthermore, we find a weak empirical evidence that the social pressure motive is relevant for explaining SRBC. Executives who have a more favourable view on the relationship between SRBC and profitability, exhibit a higher level of SRBC. The estimation results do not confirm the relevance of the so-called consumption motive, since we found no positive influence of an intrinsic value of $\mathrm{SRBC}$ on the contribution to SRBC. Introducing time discounting also 
seems superfluous, because we find a negative instead of a positive age effect. The estimation results rather tend to support the relevance of the hypothesis that religious motivated actions decrease with age, because of steep wage profiles.

Finally, it should be noted that, because of the small sample of twenty executives, our empirical test of the theoretical model is merely explorative in nature and perhaps not representative for all executives in the Netherlands. The tentativeness and preliminary nature of the findings cannot be stressed enough. The weak empirical results may not only be a consequence of the small sample in this explorative phase of the research, but also indicate that some variables are still inadequately measured or that the empirical model is missing some other explanatory variables, such as income and rate of time preference. Further research on a larger scale has to reveal whether the model is appropriate to explain the relationship between belief in the hereafter and SRBC. In that case, other possible explanatory variables, such as sex, function within the company, the sector in which the company operates, and the intensity of religious convictions, can also be taken into consideration. The theoretical model developed in this paper provides a framework to analyze the relationship between eschatological expectations and SRBC on a larger database in the future.

\section{REFERENCES}

Agle, B.R. and H.J. Van Buren III (1999), 'God and Mammon: The Modern Relationship,' Business Ethics Quarterly, 9(1), pp. 563-582.

Angelidis, J. and N. Ibrahim (2004), 'An Exploratory Study of the Impact of Degree of Religiousness upon an Individual's Corporate Social Responsiveness Orientation,' Journal of Business Studies, 51, pp. 119-128.

Azzi, C. and R. Ehrenberg (1975), 'Household Allocation of Time and Church Attendance,' Journal of Political Economy, 83(1), pp. 27-56.

Buchholtz, A.K., A.C. Amason and M.A. Rutherford (1999), 'Beyond Resources: The Mediating Effect of Top Management Discretion and Values on Corporate Philanthropy,'Business and Society, 38, pp. 168-187.

Ehrenberg, R.G. (1977), 'Household Allocation of Time and Religiosity: Replication and Extension,' Journal of Political Economy, 85(2), pp. 415-23.

Eisenberger, R. and D.M. Shank (1985), 'Personal Work Ethic and Effort Affect Cheating,' Journal of Personality and Social Psychology, 49, pp. 520528.

Fase, M.M.G. (2005), 'On Economics and Religion,' De Economist, 153(1), pp. 85-106.

Frooman, J. (1997), 'Socially Irresponsible and Illegal Behavior and Shareholder Wealth: A Meta-analysis of Event Studies,' Business \& Society, 36, pp. 221-249. 
Furnham, A. (1982), 'The Protestant Work Ethic and Attitudes Toward Unemployment', Journal of Occupational Psychology, 55, pp. 277-285.

Furnham, A. (1987), 'Predicting Protestant Work Ethic Beliefs,' European Journal of Personality, 1, pp. 93-106.

Giacalone, R.A. and C.L. Jurkiewics (2003), 'Right from Wrong: The Influence of Spirituality on Perceptions of Unethical Activities,' Journal of Business Ethics, 46, pp. 85-97.

Goff, J. Le (1986), De Woekeraar en de Hel. Economie en Religie in de Middeleeuwen, Muntinga, Amsterdam.

Graafland, J.J. (2001), 'Social and Economic Aspects in the Old Testament,' in: Henk Klok, Ton van Schaik en Sjak Smulders (eds.), Economologues. Liber Amicorum for Theo van de Klundert, Katholieke Universiteit Brabant, pp. $147-158$.

Graafland, J.J. (2002a), 'Modelling the Trade-off Between Profits and Principles,' De Economist, 150, pp. 129-154.

Graafland, J.J. (2002b), 'Profits and Principles: Four Perspectives,' Journal of Business Ethics, 35, pp. 293-305.

Graafland, J.J. and S. Eijffinger (2004), Corporate Social Responsibility of Dutch Companies: Benchmarking, Transparency and Robustness, De Economist, 152(3), pp. 1-24.

Graafland, J.J. and H. Smid (2004), 'Reputation, Corporate Social Responsibility and Market Regulation,' Tijdschrift voor Economie en Management, XLIX, April, pp. 271-308.

Graafland, J.J. and B.W. van de Ven (2006), 'Strategic and Moral Motivation for Corporate Social Responsibility,' Journal of Corporate Citizenship, 22, pp. 111-123.

Hair, J.F., R.E. Anderson, R.L. Tatham and W.C. Black (1998), Multivariate Data Analyses, Prentice Hall, New Jersey.

Hambrick, D.C. and P.A. Mason (1984), 'Upper Echelons: The Organization As a Reflection of Its Top Managers,' Academy of Management Review, 9, pp. 193-206.

Iannaccone, L.R. (1992), 'Sacrifice and Stigma: Reducing Free-riding in Cults, Communes, and Other Collectives,' Journal of Political Economy, 100(2), pp. 271-291.

Iannaccone, L.R. (1998), 'Introduction to the Economics of Religion,' Journal of Economic Literature, 36, pp. 1464-1496.

Jones, T.M. and A.C. Wicks (1999), 'Covergent Stakeholder Theory,' Academy of Management Review, 24, pp. 206-221.

Kaski (2004), Research for NCRV TV Program Schepper en CO, Radboud University Nijmegen.

Lerner, L.D. and G.E. Fryxell (1994), 'CEO Stakeholder Attitudes and Corporate Social Activity in the Fortune 500', Business and Society, 33, 58-81. 
Liedtka, J. (1991), 'Organizational Value Contention and Managerial Mindsets,' Journal of Business Ethics, 7, pp. 543-557.

Long, S.H. and R.F. Settle (1977), 'Household Allocation of Time and Church Attendance: Some Additional Evidence,' Journal of Political Economy, 85(2), pp. 409-413.

McWilliams, A. and D. Siegel (2001), 'Corporate Social Responsibility and Financial Performance: Correlation or Misspecification?', Strategic Management Journal, 21, pp. 603-609.

Orlitzky, M., F.L. Schmidt and S.L. Rynes (2003), 'Corporate Social and Financial Performance, A Meta-analysis,' Organization Studies, 24, pp. 403441.

Pava, M.L. (2003), 'Searching for Spirituality in All the Wrong Places,' Journal of Business Ethics, 48, pp. 393-400.

Posnikoff, J.F. (1997) 'Disinvestment from South Africa: They Did Well by Doing Good,' Contemporary Economic Policy, 15, pp. 76-86.

Schmitt, N. (1996), 'Uses and Abuses of Coefficient Alpha', Psychology Assessment, 8(4), pp. 350-353.

Shivesh Chandra Thakur (1969), Christian and Hindu Ethics, London, George Allen and Unwin LTD.

Stewart, H.W. (1997), 'Enlarging the Conversation,' Business Ethics Quarterly, 7(1), pp. 5-20.

Tamari, M. (1997), 'The Challenge of Wealth,' Business Ethics Quarterly, 7(1), pp. $45-56$.

Treviño, L.K., L.P. Hartman and M. Brown, (2000), 'Moral Person and Moral Manager: How Executives Develop a Reputation for Ethical Leadership,' California Management Review, 42, pp. 128-142.

Tropman, J.E. (1995), The Catholic Ethic in American Society. An Exploration of Values, San Francisco, Jossey-Bass Publishers.

Waddock, S.A. and S.B. Graves (1997), 'The Corporate Social PerformanceFinancial Performance Link,' Strategic Management Journal, 18, pp. 303319.

Weaver, G.R. and B. Agle (2002), 'Religosity and Ethical Behavior in Organizations: A Symbolic Interactionist Perspective,' Academy of Management Review, 27(1), pp. 77-97.

Werbel, J.D. and S.M. Carter (2002), 'The CEO's Influence on Corporate Foundation Giving,' Journal of Business Ethics, 40, pp. 47-60. 